\title{
Determinant of Health risk behaviours among secondary school students in Kwara State, Nigeria
}

\author{
Umar N. Jibril ${ }^{\star}$, Olusegun Badaki ${ }^{2}$, Umar Aminat ${ }^{3}$, G. Ibraheem A. M1, Kamar Abdulkadir ${ }^{1}$, \\ Imam A. Abubakar ${ }^{1}$ and Yusuf Abdulrasheed Gambari ${ }^{1}$
}

\author{
${ }^{1}$ Department of Nursing Science, College of Health Sciences, University of Ilorin, Nigeria. \\ ${ }^{2}$ Department of Science Education, Faculty of Education, Federal University, Dutsinma, Katsina State, Nigeria. \\ ${ }^{3}$ College of Education (Technical), Lafiagi, Kwara State, Nigeria.
}

*Corresponding author. Email: umaribna@gmail.com

\begin{abstract}
Copyright @ 2018 Jibril et al. This article remains permanently open access under the terms of the Creative Commons Attribution License 4.0, which
\end{abstract} permits unrestricted use, distribution, and reproduction in any medium, provided the original work is properly cited.

Received 27th July, 2017; Accepted 24th August, 2017

\begin{abstract}
Human behaviour plays a significant role in the maintenance of health, prevention of disease and disease causation; hence knowledge of health risk behaviours becomes necessary to maintain healthy life. This study examined knowledge, practice and factors associated with health risk behaviours among students in three secondary schools in Kwara State. A descriptive cross-sectional research design using a proportional cluster sampling method to select three public schools and three hundred and sixty senior secondary school students were sampled for the study. A selfdesigned questionnaire was used for data collection. Data collected were analyzed using frequency counts and percentages to answer research questions while Chi-square $\left(\mathrm{x}^{2}\right)$ was used to test hypotheses. The result revealed that $85.0 \%$ of students have knowledge about forms and factors associated with Health Risk Behaviours (HRB). It also shows that knowledge of health risk behaviours has negative impact on the student's school attendance and achievement. This study concluded that knowledge and peer group influence contributed to health risk behaviours among secondary school students in Ilorin, Kwara State. It was therefore recommended that health education on dangers of knowledge of health risk behaviours should be emphasized in schools, school environment be made free of substances been abused by the students.
\end{abstract}

Keywords: Health risk factors, health risk behaviours, knowledge, secondary school students.

\section{INTRODUCTION}

Health risk behaviour was defined as any activity undertaken by individuals with a frequency or intensity that increases risk of disease or injury (Steptoe and Wardle, 2010). Much of the morbidity or mortality is linked with individual behavioural patterns, polluted environment or poverty (Jamal et al., 2013). Smoking, illicit sex and drugs abuse, physical inactivity, poor diet, alcohol misuse behaviours and tobacco use are health risk behaviours (HRBs) identified and indicted as the leading causes of death regardless of one's age (Bell et al., 2008). Center for disease control and prevention, (2010) statistics also showed that half of the premature death from developed countries is caused by preventable behavioural factors such as tobacco use, alcohol abuse, physical inactivity, and unhealthy dietary habits, risky sexual practices, nonadherence to; effective medication regimens and screening programmes. Health risk behaviours also have negative impact on the health and influence cognitive performance, emotions, and the overall quality of life in an individual in a magnitude that has become one of the priorities of the most important national and international health organization (Gray, 2009).

World Health Organization (WHO, 2013) reports revealed that the leading causes of global deaths today are largely associated with lifestyle which is an important predictor of future health, productivity and life expectancy. The increased western world lifestyle habits during the 1990s have resulted to a decrease in healthier 
lifestyles and an increased in related diseases in the global community (Surujlal et al., 2011). Health risk behaviours were categorized into six areas: behaviours that contribute to unintentional and intentional injuries; tobacco use; alcohol and other drug use; sexual behaviours, unhealthy dietary behaviours; and physical inactivity (Mayosi, et al., 2009). Guo and Chumlea (2012), observed that peer and family influences have the greatest influence on adolescent drug use. Moses et al. (2012) studies on health risk behavioural factors among secondary school students in Okitipupa, Ondo State, Nigeria, revealed that parental influence, festivals practices, peer pressure and civilization are strong factors that facilitate HRB.

Another study which examining family and peer influences on HRB among youths discovered that peers' antisocial behaviour predicted a higher risk of drug activity, while peers' pro-social behaviour predicted a lower risk of drug activity (Jamal et al., 2013). Imaledo et al. (2012) study on pattern of risky sexual behavior and associated factors among undergraduate students of the University of Port Harcourt, Nigeria also indicated that more than a quarter of respondents who were using alcohol and many of them had taken alcohol before. These students' opinion might be because adolescents' substance abuse usually starts with alcohol and cigarette which are referred to as gateway substances. The researchers attributed easy accessibility of young people in most of our communities to these substances that are abused as factors responsible for prevalence of HRB among the students. The need to step up the call for actual ban of young people to these substances which have the ability to impede on their senses is very important and urgent. Mayosi et al. (2009) opined that most of these respondents have parents that drinks alcohol. Mayosi et al. (2009) further submitted that family conflict, family bonding, and peers' antisocial behaviours remain independent predictors of drug use among adolescence.

In most cities and towns of Kwara State particularly llorin, many health risk behaviours such as drugs and alcohol abuse, unhealthy sexual behaviours and unhealthy dietary behaviours as well as peer group influence were prominent among the adolescents. These factors have motivated youths to engage in violence, thuggery, disobedience to parents, teenage pregnancy, poor health status and poor school attendance. These health-risk behaviours were observed among the male and female secondary school students in llorin which could have negative health impacts. Violence within and outside the school environment could probably be linked with behaviours such as smoking, drug and alcohol use among the male students in government secondary schools, while, unhealthy sexual behaviours among the students could also be associated with teenage pregnancy among female students in secondary schools. It is in view of the above that we investigated into knowledge, practice and factors responsible for health risk behaviours among students in three secondary schools in Ilorin, Kwara State.

\section{METHODOLOGY}

This study adopted descriptive cross-sectional research design to examined knowledge, practice and factors responsible for health risk behaviours among students in three selected secondary schools (Government Secondary School Ilorin, Queen Elizabeth Secondary School Ilorin and Oke-Ose Community Secondary School) in Ilorin. A multi-stage sampling technique was used to sample three hundred and sixty secondary school students from the three selected secondary schools for the study. A cluster sampling method was used to select three schools in Ilorin (Kwara central senatorial district) of the State. Simple random sampling method was used to select 120 respondents from each school, that is, forty students were randomly selected from each of the senior secondary school classes (SSS1, SSS2 and SSS3) in the district.

A self-designed questionnaire known as knowledge and practice of health risk behaviors questionnaires (KPHRQ) was used for data. This questionnaire comprised of information on knowledge about health risk behaviours, factors contributing to health risk behaviours and effect of health risk behaviours on the school attendance of secondary school students. Validity of the instrument was determined by test re-test of instrument and a reliability coefficient of 0.81 was obtained. Permission for this study was sought from the heads of each school and head teacher of each class in the schools. The nature, purpose and process of this study were also explained to the students for their consent to participate in the study. Descriptive statistics of frequency count and percentages were used to answer research questions and inferential statistics of Chi square $\left(x^{2}\right)$ was used to test hypotheses.

\section{RESULTS}

Table 1 revealed the knowledge level of secondary school students about Health Risk Behaviours (HRB). Ninety-four (78.3\%) of students had adequate knowledge about HRB and majority (85.8\%) of them believed that $\mathrm{HRB}$ are unhealthy behaviours that constitute danger to the body. More than average number $(55.0 \%)$ of students identified those involved in health risk behaviours, but $65.8 \%$ of them claimed not to have been involved in any form of HRB nor have relative or family members that indulge in HRB.

Table 2 revealed factors associated with indulgence of students in health risk behaviors. The most identified risk factor among the students is the school environment $(80.8 \%)$ and peer group influence $(80.0 \%)$. This might 
Table 1. Knowledge of Students about Health risk behaviours.

\begin{tabular}{lccc}
\hline \multirow{2}{*}{ What do you understand by health risk behaviours? } & Yes & No & Not Sure \\
\cline { 2 - 4 } & Freq (\%) & Freq (\%) & Freq (\%) \\
\hline Health risk behaviours are unhealthy behaviours that constitute danger to the body & $103(85.8 \%)$ & $12(10 \%)$ & $5(4.2 \%)$ \\
Do you know about Health risk behaviours? & $94(78.3 \%)$ & $26(21.7 \%)$ & $0(0 \%)$ \\
Do you know someone that has been involved in Health risk behaviours? & $66(55 \%)$ & $48(40 \%)$ & $6(5 \%)$ \\
Have you been involved in any form of Health risk behaviours? & $29(24.2 \%)$ & $79(65.8 \%)$ & $12(10 \%)$ \\
Do you have relative or family members that indulge in Health risk behaviours? & $51(42.5 \%)$ & $61(50.8 \%)$ & $8(6.7 \%)$ \\
\hline
\end{tabular}

Table 2. Factors responsible for Health risk behaviours among Secondary School Students.

\begin{tabular}{lccc}
\hline $\begin{array}{l}\text { Do the following factors predispose/ facilitate health risk behaviours } \\
\text { among students? }\end{array}$ & Yes \% & No \% & Not Sure \% \\
\hline School environment & $97(80.8 \%)$ & $12(10 \%)$ & $11(9.2 \%)$ \\
Family structure & $86(71.7 \%)$ & $21(17.5 \%)$ & $13(10.8 \%)$ \\
Family member that indulge in Health risk behaviours & $86(71.7 \%)$ & $21(17.5 \%)$ & $13(10.8 \%)$ \\
Experimentation and curiosity & $81(67.5 \%)$ & $14(11.7 \%)$ & $25(20.8 \%)$ \\
Peer group influence & $96(80 \%)$ & $16(13.3 \%)$ & $8(6.7 \%)$ \\
\hline
\end{tabular}

probably be due to students keeping bad company and free accessibility to factors that encourage HRB in the school environment. This result found that the school environment, having family members that indulge in health risk behaviours, experimentation and curiosity and peer group influence are significant factors responsible for the indulgent of health risk behaviours among students.

$\mathbf{H}_{01}$ : there is no significant relationship between knowledge and indulgence in health risk behaviour. Table 3 revealed the relationship between the knowledge about $\mathrm{HRB}$ and indulgence of HRB among senior secondary school students with $p$-value $=0.000$, less than the significant value of 0.05 , the null hypothesis is hereby rejected. This implied that there is a significant relationship between knowledge and indulgence of HRB among senior secondary school students in llorin.

$\mathrm{Ho}_{2:}$ There is no significant relationship between health risk behaviours and students school attendance. Table 2 showed the relationship between health risk behaviours and students' school attendance with the calculated pvalue 0.000 less than the significant value of 0.05 , the null hypothesis is hereby rejected. This implied that there is significant relationship between health risk behaviours and poor students' school attendance in Ilorin, Kwara State. While,

$\mathbf{H}_{03}$ : which states that there is no significant relationship between health risk behaviours and peer group influence was rejected as shown in Table 3 . The $p$-value of 0.000 was less than the significant value of 0.05 , which implied that there is significant relationship between health risk behaviours and peer group influence among senior secondary school students in llorin.

\section{DISCUSSION}

It is a common knowledge that the greatest threat to the wellbeing of young people worldwide comes from preventable and often self-inflicted causes particularly unhealthy behaviours such as drugs and alcohol use, violence, delinquency and sexual risk taking (Bell et al., 2008). Findings from this study showed that large number $(78.3 \%)$ of students have knowledge about health risk behaviours, but the students high level of knowledge about HRB does not positively tamed the high level of students' indulgence in unhealthy behaviours. This finding is in agreement with the study on the knowledge, attitudes and behaviour of students on pattern of sexual risk behavior by Imaledo et al. (2012) and Kaaya et al. (2002) who reported that although students had good understanding of the epidemiology and effects of unhealthy sexual behaviours, but such knowledge does not necessarily reflect on the risk taking behaviours among the adolescents.

It is acknowledged that health is strongly related to students' school attendance and academic achievement in all forms of learning institutions. This study found that students who indulge in health risk behaviour are more likely to have poor school attendance. This correlates with the study carried out on the relationship between different health risk behaviours and students' academic performance. The study observed that unhealthy dietary behaviours, early sexual initiation, violence and physical inactivity are consistently linked to poor grades, test 
Table 3. Chi square $\left(\mathrm{x}^{2}\right)$ test on Health Risk Behaviours and factors among Secondary School Students in Kwara State.

\begin{tabular}{clccc}
\hline $\mathrm{H}_{0}$ & Health risk behaviours and factors & $\mathbf{X}^{2}$ & df & p-value \\
\hline 1 & knowledge about health risk behaviours and practice of HRB & 52.130 & 2 & 0.000 \\
2 & health risk behaviours and peer group influence & 132.288 & 2 & 0.000 \\
3 & health risk behaviours and student school attendance & 103.963 & 2 & 0.000 \\
\hline
\end{tabular}

scores and lower educational attainment (MacLellan et al., 2008).

This study also found that the school environment plays a significant role in facilitating health risk behaviours among students. This finding supports the research conducted by Jamal et al. (2013) on the school environment and student health which discovered four over-arching meta-themes which focused on a range of different health issues. First, aggressive behaviours and substance use are often a strong source of status and bonding at schools where students feel educationally marginalized or unsafe. Second, health risk behaviors are concentrated in unsupervised hotspots at the school. Third, positive relationships with teachers appear to be critical in promoting student wellbeing and limiting risk behaviour; however, certain aspects of schools' organization and education policies constrain this, increasing the likelihood that students look for a sense of identity and social support via Health risk behaviours. Fourth, unhappiness at school can cause students to seek sources of 'escape' either by leaving school at lunchtime or for longer unauthorized spells or through substance use.

This study further observed that peer group influence strongly constitutes a significant factor in the involvement of youths on health risk behaviours. For example, students who were in their adolescents' age who were exposed to sexual behaviour through the media were also engaging in sexual activity themselves. This finding also posited that students, who are addicted to information technology gadgets by browsing through pornographic website and reading of pornographic novels or magazines, expose them to various forms of sexual activities and health risk behaviours. This finding was in agreement with Imaledo et al. (2012) study on pattern of risky sexual behavior and associated factors among undergraduate students of the University of Port Harcourt, Nigeria.

\section{Implications health risk behaviour on the health of the students and schools}

With a wide range of knowledge and considerable skill in developing relationships with adults and adolescents, health educators, both generalist and specialized practice, are in good positions to address the problems of health risk behaviours. School health personnel in many schools have direct access to adolescents and thus have the potential for carrying out many helpful interventions to prevent or address negative behaviours. Assessing the risky sexual behaviour, alcohol use, and violence is an essential starting point, as it is important for School health personnel to ask adolescents direct questions about these issues. Failure to address these issues directly may be perceived by some adolescents as tacit permission to engage in them.

School health personnel who were the captains of school health service will find the findings of this study relevant especially during the periodic health inspection and teaching of sensitive subjects like sex education and substance abuse among secondary school students. The nurses are considered as competence. In health educators' interaction with students, it is importance to inquire about their involvement in health risk behaviours and to educate the students on the implications of such HRB to health with confident. Health educators must understand the legal and ethical implications of gaining knowledge about the behaviours of students and about where and when not to keep or divulge this information.

School health educators and health workers in primary care services often have access to parents as well as school personnel. They need to empower parents and school personnel with necessary HRB information as well as students, and to monitor students engaging in risky and dangerous behaviours in schools. In addition, health educators have the responsibility to teach school personnel and parents/guardian on how to complement the school health services in identifying health risk behaviours, preventing and control risk factors among the students.

\section{Conclusion}

Based on the findings of this study it was concluded that students' knowledge about health risk behaviours significantly influence their indulgence in HRB among senior secondary schools in Ilorin. Student's health risk behaviours contributed to poor school attendance among students in Ilorin. This study also concluded that students peer group influence contributed greatly to students health risk behaviours among senior secondary schools in llorin. The indulgence of students in different forms of new health risk behaviours such as glue sniffing and browsing into pornographic website have been found to be increase among secondary school students over the years. 


\section{Recommendations}

Based on the conclusion of this study, the following recommendations were made that school authority need to develop student awareness programmes aimed at improving knowledge of students on the dangers of indulgence in HRB. School health services need to conduct a screening exercise to identify students that indulges in HRB with aim to discourage them from such act thus improve their school attendance. Improvement for health and counseling services at the school level is needed to help identify health risk behaviours among students. Security checks should be mounted to apprehend and punish students and peer groups found indulging in health risk behaviours in schools.

\section{CONFLICT OF INTEREST}

The authors declare that they have no conflict of interest.

\section{ACKNOWLEDGEMENT}

We appreciated the ethical approval by the state ministry of education Kwara State and the management of the selected schools for the conduct of this study. The research assistants and students' participation in this study were commendable.

\section{REFERENCES}

Bell, C. C., Bhana, A., Peterson, I, Mckay, M.M., Gibeons, R., Bannon, W., \& Amatya, A. (2008). Building Protective Factors to Offset Sexual Risky Behaviours among Black Youths: A Randomised Trial. Journal of National Medical Association, 100(8), 936-944.

Center for Disease Control and Prevention (2010). Web-based injury statistics query and reporting system. Available at: www.cdc.gov/ncipc/wisqars. Accessed June 4th, 2016.

Gray, A. (2009). World Health and Disease. Buckingham. Open University Press.
Guo, S. S., \& Chumlea, W. C. (2012). Tracking of body mass index in children in relation to overweight in adulthood. The American Journal of Clinical Nutrition, 70(1), 1455S-1458S.

Imaledo, J.A., Peter-Kio, O. B., \& Asuquo, E. O. ( 2012). Pattern of risky sexual behavior and associated factors among undergraduate students of the University of Port Harcourt, Rivers State, Nigeria. The Pan African Medical Journal, 12, 97.

Jamal, J., Fletcher, A., Wells, H., Thomas, J., \& Bonnell, C. (2013). The school environment and student health: a systematic review and mete-ethnography of qualitative research. BMC Public Health. 13, 798.

Kaaya, S. F., Flisher, A. J., Mbwambo, J. K., Schaalma, H., Aaro, L. E., \& Klepp, K. I. (2002). A Review of studies of Sexual Behaviours of School Students in Sub-Saharan Africa. Scandinavian Journal of Public Health, 30, 148-160.

MacLellan, D., Taylor, J., \& Wood, K. (2008). Food intake and academic performance among adolescents. Canadian Journal of Dietetic practice and Research, 69(3), 141-144.

Mayosi, B. M., Flisher, A. J., Lalloo, U. G., Sitas, F., Tollman, S. M., \& Bradshaw, D. (2009). The burden of non-communicable diseases in South Africa. The Lancet, 374(9693), 934-947.

Moses, M. O., Lokoyi, O. L. O., \& Falola, K. O. (2012). Health Risk Behavioural Factors among Secondary School Students: A Challenge to Life Expectancy in Okitipupa, Ondo State, Nigeria. Journal of Medical Sciences, 2(2), 33-37.

Steptoe, A., \& Wardle, J., (2010). Health related behaviour: prevalence and links with disease. In A, Kaptein \& J. Weinmen, (Eds.), Health psychology. BPS: Blackwell.

Surujlal. J., Nolan, V. T., \& Ubane, T. (2011). Drinking patterns and related consequences among university student-athletes. African Journal for Physical, Health Education, Recreation and Dance, 18(2), 281-292.

World Health Organization (WHO) (2013). Global Health Observatory: Non communicable disease mortality and morbidity. 